\title{
THE FINNISH-POLISH-UKRAINIAN SUMMER SCHOOL IN COMPLEX ANALYSIS OPENING ADDRESS
}

Immanuel Kant, one of the most profound idealist philosophers, said once that in every cognition there is as much science as there is mathematics in it. These words, particularly when we remember Hugo Steinhaus' maxim that it is mathematics that mediates between matter and spirit, seem to emphasize the unique and universal character of this branch of science.

For many centuries now mathematics has been considered a discipline whose presence and influence can be traced in numerous branches of knowledge. It is this particular field that was the subject of studies of many scientists and philosophers as far back as Antiquity - first of all the Pythagorean Society, Democritus and Plato, who perceived the material world in mathematical categories. Unfortunately, the overwhelming scientific authority of Aristotle, the most ingenious ancient methaphysicist, scientist, logician and ethicist, stopped the development of science for one and a half thousand years, because, unlike the Pythagorean School and Plato, Aristotle perceived the material world in a qualitative and not quantitative way. Modern science, by which I mean a detailed quantitative understanding of the material world expressed in the form of mathematical equations, was born first of all due to medieval scholars such as the so-called "calculatores" at the University of Oxford, William Ockham, and Ioannes Buridanus of Paris, and then due to their great continuators, Galileo and Newton. Both the above-mentioned medieval scholars and the modern scientists, Galileo and Newton, returned to the quantitative and mathematical conception of the material world. This mathematical, detailed knowledge of the world is the essential basis of all modern technology.

We are so familiar with the presence of science in our lives, and the multitude of its technological applications, that we easily forget that this is a unique feature of our European civilization. Nothing similar is found in any of the great civilizations of Antiquity. We find in them, of course, highly developed social structures, great cities, men and women of high culture, great works of art, architecture, philosophy, and literature - but no science as we know it today.

The most important tool as well as framework for modern science is mathematics. It is an area deeply rooted in European culture - the culture that derives so much from Greek philosophy, Roman law, Judaism and medieval Arab science; the culture that was developed and finally shaped by Christianity, and which includes such values and atti- 
tudes as: universalism, openness to freedom, truth, democracy, moral good and tolerance; acceptance of both the spiritual and material world; the conviction that the whole cosmos is rational, ordered and that it is possible and even indispensable to get to know it; that knowledge is for everyone and not for the initiated; that man is the biggest temporal value, but, apart from laws granted to him, he also has duties towards others; that, at the foundations of true, responsible freedom, there must always be a fair law.

The Catholic University of Lublin, renown so far for its humanistic character, is now going to extend its scope of education. A modern European alma mater feels a need for including in the curriculum the subject that crosses disciplinary boundaries and, at the same time, unites different bodies of knowledge.

The Finnish-Polish-Ukrainian Summer School in Complex Analysis is an opportunity to show mathematics at work, to exhibit the way it works out the most practical thing in the world - a good theory; it is, simultaneously, an opportunity to announce the birth of mathematics at the Catholic University of Lublin, a major step towards broader, better and more universal education.

As the Rector of the Catholic University of Lublin I would like to welcome all the distinguished scholars from all over the world, among them Bogdan Bojarski, Frederick Gehring, Ilpo Laine, Olli Martio, Promarz Tamrazov and Jussi Väisälä. I wish all participants of the School coming up with good ideas and theories and also a nice stay at the Catholic University of Lublin.

Let me cordially welcome the Dean of the Faculty of Philosophy of the Catholic University of Lublin, Professor Zofia Zdybicka. In a very special way, I would like to express my gratitude to Professors Ławrynowicz and Zając, Dr. Partyka and Mr. Kawa who have prepared this Fifth Finnish-Polish-Ukrainian Summer School in Lublin.

Stanistaw Wielgus 